\title{
Public Health Surveillance: Challenges and Solutions for the Road Ahead
}

\author{
Lipika Nanda ${ }^{1,2}$ and Sandeep Mahapatra*1 \\ ${ }^{1}$ Indian Institute of Public Health Bhubaneswar (IIPHB), Bhubaneswar, India; ${ }^{2}$ Public Health Foundation of India (PHFI), Delhi, India
}

\section{Objective}

Aim

To setup a nodal agency called the Centre for Public Health Preparedness (CPHP) dedicated towards public health surveillance during disasters in the state of Odisha, India.

For better public health preparedness in disaster management the objectives of CPHP will be to:

1. To strengthen public health surveillance and preparedness for disaster management, through research, capacity building and action.

2. To act as a comprehensive technical support unit and resource centre for State Government of Odisha, India on public health preparedness for disaster management and to eventually provide similar support to other states of India.

3. To collaborate with National Disaster Management Authority to provide support in surveillance, preparedness and capacity building during public health emergencies.

4. To become a national centre of excellence in the area, in due course of time.

\section{Introduction}

The vulnerability of mankind to disasters of various types has increased considerably all over the world ${ }^{1}$. The situation in India is not better since 55 per cent of India's landmass is prone to earthquakes; 68 per cent is vulnerable to drought; 12 per cent to floods; and 8 per cent to cyclones apart from the heat waves, and severe storms ${ }^{2}$. Odisha, one of the developing coastal states of India, with a coastline of around $495 \mathrm{~km}$ and a population of about 43 million, is most prone to natural disasters like super cyclones and major floods every year. It has witnessed and suffered a number of super cyclones and floods in the last ten years. Such conditions give rise to various health hazards and diseases.

Such an environment demands for a nodal agency which is dedicated towards public health surveillance during disasters in the state of Odisha, India. This paper tries to put forth the goals, requirement and role in setting up a centre for disaster preparedness for preparedness and surveillance during disaster. The paper also discusses various challenges and roadblocks in establishing such an institute.

\section{Methods}

Public Health Foundation of India (PHFI) with collaboration and able guidance from National Disaster Management Authority (NDMA), India proposes to set up an organization called the Centre for Public Health Preparedness (CPHP), targeting public health surveillance during disasters. The initiative in the state of Odisha, India will be implemented by Indian Institute of Public Health, Bhubaneswar (IIPHB). Indian Institute of Public Health, Bhubaneswar is one of the four institutes set up by Public Health Foundation of India (PHFI) as a part of its charter to build public health capacity in India.

Suggested Structure of the Centre for Public Health Preparedness

The proposed Centre of Excellence/Technical Support Unit would have a team of multi-disciplinary professionals as a strategic unit shown in figure 1.

\section{Results}

\section{Expected results}

The CPHP for disaster management will bring together experts from across the state of Odisha, country and internationally, to set standards for data collection, sharing, and reporting during and after a public health disaster. Concretely, this means investing time and resources also in the informal networks that can detect rumours, other alerts, the laboratory network and transport of samples for verification of immediately notifiable diseases more commonly in place. Information will be shared regularly with partners to strengthen the early warning component of disease surveillance in crises. Through the work of the CPHP, morbidity and mortality surveillance tools and training materials can also be developed.

\section{Conclusions}

The various perspectives of CPHP should be considered to develop strong health surveillance systems during disasters. There is potential for a better surveillance system to provide new capabilities in responding to public health emergencies.

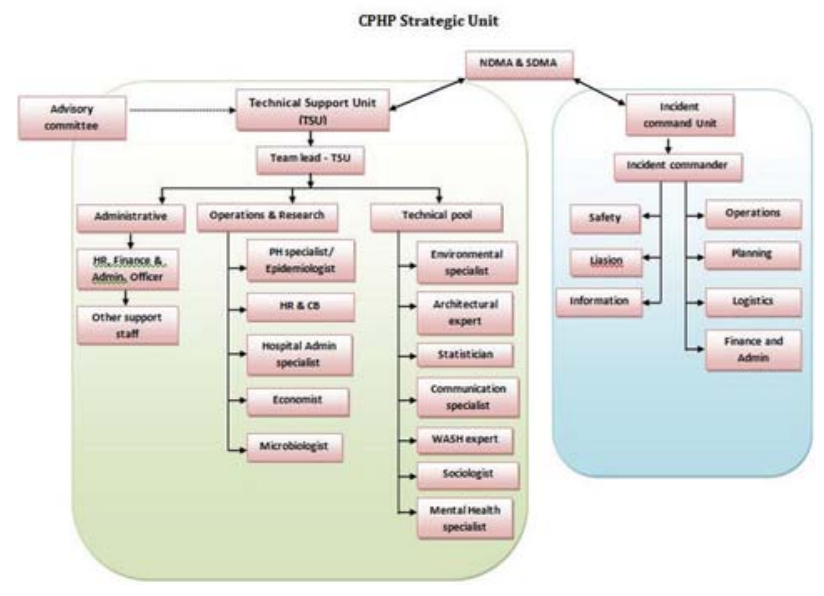

\section{Keywords}

Disaster Preparedness; Surveillance; disaster management

\section{References}

1. Kesavan P.C and Swaminathan M.S 2006. Managing extreme natural disasters in coastal areas.Phil.Trans. R.Soc.A, 364.

2. Public Policy Towards Natural Disasters in India, Centre for Budget and Government Accountability

Available at http://www.cbgaindia.org/files/working_papers/Public\%20 Policy $\% 20$ towards $\% 20$ Natural $\% 20$ Disasters $\% 20$ in $\% 20$ India. pdf, accessed on July 03, 2014.

\section{*Sandeep Mahapatra}

E-mail: sandeep@iiphb.org 